COMMENT

DOI: $10.1057 /$ s41599-018-0072-1

\title{
Integrity and Its counterfeits: implications for economy, business and management
}

William Sun ${ }^{1}$, Simon Robinson ${ }^{1} \&$ Paweł Łukasz Polowczyk ${ }^{2}$

\begin{abstract}
While the concept of integrity has long been explored by great philosophers and thinkers, its application in modern and postmodern business and economic contexts has been underdeveloped. Little have been done to address the vagueness and paradoxicality of integrity and its shadow reality of counterfeits. The thematic collection, which this paper complements, entitled 'Integrity and Its Counterfeits: Implications for Economy, Business and Management', makes a contribution towards filling the gap between the abstract concept of integrity and its application into business and economy, with a particular attention on the ambiguous, equivocal and diverse meanings of the concept, the complex and dynamic practicality of integrity, and the grey and dark areas of business out of integrity. This article introduces the background of the research theme and provides exemplary debates and emerging avenues of discussion on this topic.
\end{abstract}

\footnotetext{
${ }^{1}$ Leeds Beckett University, Leeds, West Yorkshire, United Kingdom. ${ }^{2}$ Social Sciences, University of Gdansk, Mazowsze, Warsaw, Poland. Correspondence and requests for materials should be addressed to W.S. (email: X.Sun@leedsbeckett.ac.uk)
} 


\section{Introduction}

eople would openly agree that integrity is all we admire and strive for in our lives. It is rare that someone comes to reject integrity. But ironically, non-integrity is everywhere, as what is said does not always mean or translate into what is done. Individual dishonesty and unsoundness is a commonplace. The same is for organizations. In the business world, almost all companies claim for integrity in their mission, vision or value statements. For example, 'We act with integrity in all we do'; 'We hold honesty and integrity as our guiding principles'; 'We are proud of the integrity, sincerity and transparency our employees demonstrate every day'. However, irresponsible and corrupted business behaviours and actions have never stopped, but are prevalent in our current times (OECD, 2015). So often we see the opposite of integrity as well as counterfeit integrity. This contradictory phenomenon of integrity is a subject of inquiry that has unfortunately received little attention in academics and business practice. The concept of integrity has been explored by great philosophers and thinkers for over 2000 years. But its application into modern and postmodern business and economic contexts has been underdeveloped. The main application is seen in organization behaviour and HRM literature (Becker, 1998; Blumberg, 2016), marketing research (Abela and Murphy, 2008), or business ethics (dealing with corporate moral dilemma) (Kaptein and Wempe, 2002). Little have been done to address the vagueness and paradoxicality of integrity and the shadow realities of integrity such as non-integrity, pseudo-integrity and fake integrity. The thematic collection, which this paper complements, aims to make contributions towards filling the gap between the abstract concept of integrity and its application into business and economy, with a particular attention to the ambiguous, equivocal and diverse meanings of the concept, the complex and dynamic practicality of integrity, and the grey and dark areas of business out of integrity (Robinson, 2016b; Schwartz, 2016; Bauman, 2017; Jagiello-Rusilowski, 2017; Kuokkanen, 2017; Polowczyk, 2017). In what follows, we highlight some key areas of debate and emerging avenues of discussion, which serve as exemplars to draw wider attentions to the subject and stimulate more interests in this research area.

\section{The concept of integrity}

The concept of integrity is more ambiguous than clear-cut, as people tend to define, understand and use it divergently (Audi and Murphy, 2006). It deserves us to deeply explore and clarify the concept when it is applied to economic and business contexts. Several debates can be found in relation to the concept. First of all, does the concept of integrity have moral meanings? For many, this is obvious, as integrity refers to strict adherence to a particular moral code or a value/belief system. But others deny its moral connotation and prefer its moral neutrality. For instance, the well-known Harvard professor Michael Jensen sees the mixture of integrity with morality and ethics as a conceptual confusion and insists on a positive rather than normative account of integrity (Jensen, 2009). Erhard et al. (2009) define integrity as a matter of person's word, nothing more and nothing less. When you honour your word, your word is whole and complete; when your word is whole and complete, your identity is whole and complete; when your identity is whole and complete, you are unbroken, unimpaired, sound and complete, which becomes the state and condition of integrity. For Jensen and others, integrity is a natural concept like law of gravity-if you break it you will get hurt, which has nothing to do with good vs. bad, or right vs. wrong behaviour.

Jensen's view brings out a further question here: if integrity is defined in terms of morality and ethics, how could we make a distinction between those supposed-to-be-different concepts? Robinson (2016a) sees the danger of simply making integrity into a synonym for ethics qua ethics and expands integrity to an organizational level that encompasses identity, taking responsibility for values and worth, and deliberating with others about shared narratives. Pearson (1995) strongly argues that the concept of business ethics is of little practical value to business managers, as it is full of conflicting arguments and dilemmas without any definitive answers. Instead, integrity can be clearly defined as staying 'being good' based on enlightened self-interest to maintain long-term relationships with stakeholders for the long-term success of the firm. Maxwell (2003) shares a similar view that there is no such thing as business ethics and there is only one rule for decision-making: 'Do unto others as you would have them do unto you'. People can live with integrity by using the Golden Rule as their standard, regardless of religion, culture or circumstances.

This simpler and unsophisticated definition of integrity involves a further debate on how to treat self-interest in integrity. On a moral perspective, integrity prompts a higher purpose and social value beyond self-interest. In other words, integrity is disinterested or focused on core purpose that transcends particular interests (Khurana, 2007). But Friedman (1970) and Sternberg (2000) clearly disagreed. For them, the purpose of business is by design to make profit. Corporate social responsibility is already reflected in doing so (i.e., making profits in order to serve shareholders, satisfy other stakeholders, and benefit the society). Without profit, they can do nothing or little. Adam Smith (1970) asserts that only self-interest can fundamentally motivate people to engage in business and supply goods and services to people in demand. For those classical and neo-classical economists, business integrity is simply to do your designated job and ensure successful performance. The moral position of business is to stick to the purpose of business and stay within the rule of the game; nothing else.

There are more issues in connection with the moral concept of integrity. For example, is integrity a means or end? Integrity is often treated as a means in order to serve a purpose. There are not lacking interviews, case studies and textbooks telling you that if you stay with integrity you will gain competitive advantage for business success (e.g., Gostick and Telford, 2008; Cloud, 2009; Barlow, 2017). This is the business case for integrity with which we are all familiar. But if integrity is treated as means, it tends to violate its moral intention and ethical principle. Yet, if integrity ends in itself, the question becomes: for what purpose is the concept in use? This seems to be a conceptual dilemma. Further complicating this dilemma are the facts that integrity can be immoral or amoral if it does not stick to a moral code, that moral integrity can be unethical if it sticks to a bad moral code, and that false moral integrity can be good if it imitates bad morality for a good purpose (see Polowczyk, 2017, in this collection).

A further question with the concept of integrity is whether integrity is purely an individual virtue. For many, integrity is one of most important ventures, a super verdure, or a virtue connecting with other virtues (e.g., Tullberg, 2012). For others, integrity is less about possessing something already given, but more about practising it through learning, dialoguing and developing with others to form the basis of trust (e.g., Robinson, 2016a, b). Integrity is also not purely an individual attribute, but a moral commitment in interaction with and shared by other community members (Bauman, 2013).

A more challenging question is whether integrity is universally defined or contextually based. In ordinary use, integrity means honesty, coherence, consistency and incorruptibility. It has a moral connotation as to stick to particular moral principles. The same definition is applicable to business integrity, referring to 
business ability to act with honesty, transparency, consistency and morality (e.g., the Financial Times lexicon ${ }^{1}$ ). Most of the definitions we have found, whether similar or different, tend to be universally applied, regardless of any contexts. However, people may also argue that integrity can only be understood in context (Pearson, 1995) or in its sociomoral setting (Kohlberg, 1984). It is suggested from them that understanding integrity should not be based on any abstract form as if it were pre-given or imposed from an extraneous value system, but located in a contextual setting where people perceive integrity from their own perspectives. The concept of integrity is only valuable in its practical use and in people's experiences. In this sense, the meanings of integrity tend to be pluralistic rather than universalistic.

\section{Counterfeit integrity}

Business integrity is crucial for success because integrity enables trust, without which business cannot be run. But today integrity seems to be rare and most people believe that businesses are corrupt (OECD, 2015). This is in stark contrast to businesses' high-profile claim that they are maintaining integrity, just like they claim that they are socially responsible. Inevitably we see various counterfeits of integrity in business practice, that is, they pretend to have integrity, but in fact they do not hold, engage with, or practise it. The counterfeits have become rampant that we are often not easy to discern whether it is real or false integrity. The counterfeits have tarnished and eroded the reputation and original dignity of the concept of integrity, imposed costs on those who are genuine in integrity, and suppressed business leaders' motivations towards true integrity. Thus, it becomes more important, yet more challenging, to investigate and examine counterfeits of integrity, the dark and grey sides of the shadow integrity, than to purely focus on the bright realm of integrity.

Counterfeit integrity may come out in various formats. The counterfeit may be intentional, where one presents a persona of goodness to mask opposing practices, such as 'green washing', or simply decorate it as window dressing, or act as a deliberate part of the marketing image (Pearson, 1995). It may equally be unintentional. The counterfeit integrity may go against the core principles of the profession, but you may not be aware of this; with these principles replaced by a different pressing purpose with its own imperatives and deadlines (Robinson, 2016a).

Interesting or not, the concept of counterfeit integrity tends to be complicated and subtle, as distinction can always be made between its abstract and concrete forms. In theory, counterfeits come against the moral principle of integrity and is thus unethical and bad. But in practice, as Polowczyk (2017, in this collection) argues, counterfeit integrity may be either ethically good or bad, depending on the quality of accepted morality in context. Counterfeit integrity is ethically good if the local morality is bad. Thus, counterfeit in its various forms (camouflage, appearance, simulacra and stratagem) can be ethically good in any hostile and corrupt environment. This turns out to indicate that there are always complex situations where the true meanings of integrity and its counterfeits need to be carefully examined in context.

\section{Conclusion}

The current prevalence of business misconduct and its grave consequences have urgently demanded the very necessary investigation into the importance of business integrity and its functional role in reversing the continuing sentiment of 'business as usual'. While integrity and its counterfeits have received little attention in the literature, we call for more interest from scholars, researchers, consultants and business practitioners in deeply exploring the questions, puzzles and subtleness surrounding the sophisticated phenomena of integrity and counterfeit integrity.
We have provided some exemplary debates and emerging avenues of discussion as above, which certainly do not exhaust the long list of inquiry onto this mystery subject. We welcome all the high-quality papers, whether conceptual or empirical, qualitative or quantitative, which make significant contributions to this research area, and advance, refresh and enrich our understandings of the complexity and dynamics of business integrity in practice.

Received: 24 January 2018 Accepted: 24 January 2018

Published online: 20 February 2018

\section{Notes}

1 Available at www.ft.com/lexicon

\section{References}

Abela AV, Murphy PE (2008) Marketing with integrity: ethics and the servicedominant logic for marketing. J Acad Mark Sci 36(1):39-53

Audi R, Murphy PE (2006) The many faces of integrity. Bus Ethics Q 16(1):3-21 Bauman D (2017) Integrity and justice: what is required of free market participants? Palgrave Communications 3:17046. https://doi.org/10.1057/ palcomms.2017.46

Bauman DC (2013) Leadership and the three faces of integrity Leadersh Q 24 (3):414-426

Barlow A (2017) Profiting from integrity: how CEOs can deliver superior profitability and be relevant to society. Routledge, London

Becker TE (1998) Integrity in organizations: beyond honesty and conscientiousness Acad Manag Rev 23(1):154-161

Blumberg JG (2016) Return on integrity: the new definition of ROI and why leaders need to know it. Greenleaf, Austin, Texas

Cloud H (2009) Integrity: the courage to meet the demands of reality. HarperBusiness, Glasgow

Erhard W, Jensen MC, Zaffron S (2009) Integrity: a positive model that incorporates the normative phenomena of morality, ethics, and legality (abridged version). Harvard Business School NOM Unit Working Paper No. 06-11. SSRN. https://ssrn.com/abstract $=920625$

Friedman M (1970) The social responsibility of business is to increase its profits. The New York Times Magazine, 13 Sept

Gostick A, Telford D (2008) The integrity advantage. Gibbs M. Smith, Layton, Utah

Jagiello-Rusilowski A (2017) Drama for developing integrity in higher education. Palgrave Communications 3:29. https://doi.org/10.1057/palcomms.2017.29

Jensen MC (2009) Integrity: without it nothing works. Interview by Karen Christensen, Rotman Fall:16-20

Kaptein M, Wempe J (2002) The balanced company: a theory of corporate integrity.Oxford University Press, Oxford

Khurana R (2007) From higher aims to hired hands: the social transformation of American Business Schools and the unfulfilled promise of management as a profession.Princeton University Press, Princeton

Kohlberg P (1984) The psychology of moral development: the nature and validity of moral stages (Essays on moral development, Vol 2). Harper \& Row, San Francisco

Kuokkanen H (2017) Fictitious consumer responsibility? Quantifying social desirability bias in corporate social responsibility surveys. Palgrave Communications 3:16106. https://doi.org/10.1057/palcomms.2016.106

Maxwell JC (2003) There's no such thing as “Business" ethics: there's only one rule for making decisions. Hodder \& Stoughton, London

OECD (2015) Corporate governance and business integrity: a stocktaking of corporate practices. OECD, Paris

Pearson G (1995) Integrity in Organizations: An Alternative Business Ethic. McGRW-HILL, London

Polowczyk PŁ (2017) Organizational ethical integrity: good and bad illusions. Palgrave Commun 3:46

Robinson S (2016a) The practice of integrity in business. Palgrave Macmillan, London

Robinson S (2016b) Integrity and its counterfeits: Shakespeare's Henriad. Palgrave Communications 2:16068. https://doi.org/10.1057/palcomms.2016.68

Schwartz J (2016) Integrity: the virtue of compromise. Palgrave Communications 2:16085. https://doi.org/10.1057/palcomms.2016.85

Smith A (1970) The wealth of nations. Penguin Books, London

Sternberg E (2000) Just business. Oxford University Press, Oxford

Tullberg J (2012) Integrity-clarifying and upgrading an important concept for business ethics Bus Soc Rev 117(1):89-121 


\section{Additional information}

Competing interests: The authors declare no competing financial interests.

Reprints and permission information is available online at http://www.nature.com/ reprints

Publisher's note: Springer Nature remains neutral with regard to jurisdictional claims in published maps and institutional affiliations.

Open Access This article is licensed under a Creative Commons Attribution 4.0 International License, which permits use, sharing, adaptation, distribution and reproduction in any medium or format, as long as you give appropriate credit to the original author(s) and the source, provide a link to the Creative Commons license, and indicate if changes were made. The images or other third party material in this article are included in the article's Creative Commons license, unless indicated otherwise in a credit line to the material. If material is not included in the article's Creative Commons license and your intended use is not permitted by statutory regulation or exceeds the permitted use, you will need to obtain permission directly from the copyright holder. To view a copy of this license, visit http://creativecommons.org/ licenses/by/4.0/.

(c) The Author(s) 2018 